\title{
Prey selectivity of the fringed filefish Monacanthus ciliatus (Pisces : Monacanthidae): role of prey accessibility
}

\author{
William H. Clements and Robert J. Livingston \\ Department of Biological Science, Florida State University, Tallahassee, Florida 32306, USA
}

\begin{abstract}
Laboratory experiments were conducted to measure prey selectivity of the fringed filefish Monacanthus ciliatus. Prey included 3 species of gammarid amphipods: Elasmopus levis, Melita appendiculata (Melitidae), and Lembos unicornis (Aaridae). The relative vulnerability of these species to predation was determined to be a function of their frequency of encounter. L. unicornis, a strikingly pigmented species, was disproportionately consumed by filefish when placed in experimental aquaria with equal numbers of either $E$. levis or $M$. appendiculata. We suggest that this species was encountered more frequently and therefore was more accessible to predation owing to its unique pattern of pigmentation. Results of these experiments were consistent with field data on selectivity of $M$. ciliatus.
\end{abstract}

\section{INTRODUCTION}

Observed patterns of prey selectivity are the result of predator preferences and/or differences in prey accessibility (Vinyard and O'Brien, 1976). Selectivity for a particular prey species is determined by comparison of its relative abundance in diet and habitat; numerous indices have been proposed to quantify this relationship (Ivlev, 1961; Jacobs, 1974; Chesson, 1978; Greenwood and Elton, 1979; Paloheimo, 1979; Strauss, 1979; Johnson, 1980). However, because estimates of relative prey abundance in the field are often dependent on sampling methodology, it may be difficult to distinguish between prey selectivity and sampling bias (O'Brien and Vinyard, 1974). In addition, some species found in a particular habitat may not be available to the predator; therefore it is often necessary to make highly subjective decisions regarding which species should be included in the analysis (Johnson, 1980). Finally, selectivity values reveal nothing about the relative importance of predatory preferences and prey accessibility. We submit that the actual mechanism of prey selectivity may be more interesting than the values themselves.

Prey selectivity can be measured more precisely in the laboratory, where prey abundance and accessibility can be manipulated. In this study, we report results of laboratory experiments examining selectivity of the fringed filefish Monacanthus ciliatus for 3 species of gammarid amphipods. These results are compared to patterns of selectivity of $M$. ciliatus in the field.

\section{MATERIALS AND METHODS}

Filefish were collected with a $5 \mathrm{~m}$ otter trawl from a grassbed located in Apalachee Bay, Florida (see Livingston, 1975, for details of this site), and immediately transported to the Florida State University Marine Laboratory. Fish were held in $120 \mathrm{l}$ aquaria equipped with flow-through seawater. Salinity and seawater temperature varied with ambient conditions at the FSU Marine Laboratory (30 to $33 \mathrm{ppt;} 23$ to $26^{\circ} \mathrm{C}$ ). The fish were acclimated to laboratory conditions for $3 \mathrm{wk}$ on a $12 \mathrm{~h}$ day/night cycle and maintained on a diet of live amphipods, polychaetes, bivalves, and seagrass, the dominant food items in the diet of filefish in the field (Clements and Livingston, 1983). Fish were starved for $48 \mathrm{~h}$ prior to the start of an experiment. All experiments were conducted from August to November 1981, between 1100 and $1400 \mathrm{~h}$.

Amphipods were collected using plastic fruit bags filled with artificial substrata, which were placed in a 
grassbed located $100 \mathrm{~m}$ south of the marine laboratory. Substrata were colonized within 10 to $14 \mathrm{~d}$ by several species of gammarid amphipods. The 3 dominant species, Lembos unicornis (Aoridae), Elasmopus levis and Melita appendiculata (Melitidae), were sorted and held in separate 201 aquaria with flow-through seawater.

Experiments were conducted in 201 aquaria under constant illumination. In all experiments, except the increased shelter experiment, $45 \mathrm{~g}$ (wet weight) of the red algae Digenia simplex were defaunated by vigorous shaking in fresh water and then placed in each aquarium as a substratum. This particular alga is inhabited by several species of amphipods in Apalachee Bay, including the 3 species used in our experiments (Lewis, 1982).

Initial patterns of prey selectivity were determined by placement of 50 amphipods, 25 individuals each of 2 species (Lembos unicornis and Elasmopus levis or L. unicornis and Melita appendiculata), in an aquarium. The third possible combination ( $E$. levis and M. appendiculata) was not considered because of the difficulty of obtaining adequate numbers of these 2 species. Because similar size distributions were needed, amphipods were placed over a grid $11 \mathrm{~mm}$ squares) in a large Petri dish containing seawater, and individuals of the 2 species were paired with respect to size. Experiments were started when all amphipods were on the algal substrata (approximately 15 to $30 \mathrm{~min}$ ), after which a single 40 to $50 \mathrm{~mm}$ filefish was placed in the aquarium and allowed to feed for $1 \mathrm{~h}$. Any fish not observed feeding within $5 \mathrm{~min}$ was replaced by another individual. At the end of the feeding bout, the fish was removed and the remaining amphipods were removed, counted, and identified to species.

The effect of relative prey abundance on selectivity was measured by a shift of the initial prey ratio from
$1: 1$ to $4: 1$ in favor of the less 'preferred' species, as determined from the equal-density experiments. Effects of increased shelter on selectivity and predation intensity were determined for equal numbers (25 individuals each) of Lembos unicornis and Elasmopus levis by a doubling of the amount of algae to $90 \mathrm{~g}$.

Each of the above experiments was replicated 6 times, using a different fish for each replicate. Deviation from random foraging was measured using a replicated chi-square test for goodness of fit (Zar, 1974). Expected frequencies were derived from the data, based on the null hypothesis that prey species were consumed in proportion to their relative abundance. In this analysis, the total chi-square value was partitioned into 2 components, the pooled and the heterogeneity chi-square. When the heterogeneity chi-square was not significant, indicating the 6 replicates were from the same population, the pooled chi-square was used to test the fit of the data to the expected frequencies (Zar, 1974). Yates' correction for continuity was applied to these data to reduce potential bias in chisquare when only 2 classes (e.g. 2 species) are involved in goodness of fit tests.

Attack rates on Lembos unicornis and Elasmopus levis were measured by placement of 50 individuals of each species in separate aquaria with $45 \mathrm{~g}$ of red algae. A single filefish was then introduced into each aquarium and was observed searching for prey for $5 \mathrm{~min}$. The timer was stopped during the handling phase of each successful attack to standardize search time between fish. The total number of attacks (successful and unsuccessful) per 5 min search time was recorded. The experiment was replicated 6 times for each species, using a different fish for each replicate.

Prey selectivity of Monacanthus ciliatus in the field was estimated using Stoner's (1980) data on relative abundance of amphipods in Apalachee Bay and gut analysis of 54 individuals collected from the same area

Table 1. Results of selectivity experiments conducted at equal prey density. Expected $=p_{i} \times N$, where $p_{1}$ is the proportion of species $\mathrm{i}$ initially and $\mathrm{N}$ is the total number of amphipods consumed. $\mathrm{SD}=$ standard deviation. Pooled chi-square values were calculated using Yates' correction for continuity. Pooled and heterogeneity chi-square values were tested with 1 and 5 degrees of freedom, respectively

\begin{tabular}{|c|c|c|c|c|c|c|c|}
\hline \multirow[t]{2}{*}{ Species } & \multirow{2}{*}{$\begin{array}{c}\text { Initial } \\
\text { density }\end{array}$} & \multicolumn{3}{|c|}{ Mean number consumed } & \multirow{2}{*}{$\begin{array}{l}\text { Percent } \\
\text { consumed }\end{array}$} & \multicolumn{2}{|c|}{ Chi-square } \\
\hline & & expected & observed & $\mathrm{SD}$ & & pooled & heterogeneity \\
\hline E. levis & 25 & 16.4 & 13.0 & 3.9 & 52.0 & \multirow{2}{*}{$8.12^{\circ}$} & \multirow{2}{*}{1.40} \\
\hline L. unicornis & 25 & 16.4 & 19.8 & 3.3 & 79.2 & & \\
\hline Total & 50 & - & 32.8 & 6.9 & 65.6 & \multirow{4}{*}{$10.54^{\cdots}$} & \multirow{4}{*}{2.56} \\
\hline M. appendiculata & 25 & 11.5 & 8.2 & 2.3 & 32.8 & & \\
\hline L. unicornis & 25 & 11.5 & 14.7 & 2.5 & 58.8 & & \\
\hline Total & 50 & - & 22.9 & 3.3 & 45.8 & & \\
\hline
\end{tabular}


Table 2. Results of selectivity experiments conducted at unequal prey density. Statistical notation and analysis are the same as in Table 1

\begin{tabular}{|c|c|c|c|c|c|c|c|}
\hline \multirow[t]{2}{*}{ Species } & \multirow{2}{*}{$\begin{array}{c}\text { Initial } \\
\text { density }\end{array}$} & \multicolumn{3}{|c|}{ Mean number consumed } & \multirow{2}{*}{$\begin{array}{l}\text { Percent } \\
\text { consumed }\end{array}$} & \multicolumn{2}{|c|}{ Chi-square } \\
\hline & & expected & observed & $\mathrm{SD}$ & & pooled & heterogeneity \\
\hline E. levis & 40 & 28.6 & 27.7 & 4.1 & 69.3 & \multirow{2}{*}{0.65} & \multirow{2}{*}{0.54} \\
\hline L. unicornis & 10 & 7.1 & 8.0 & 1.7 & 80.0 & & \\
\hline Total & 50 & -- & 35.7 & 6.8 & 71.4 & \multirow{4}{*}{0.28} & \multirow{4}{*}{0.80} \\
\hline M. appendiculata & 40 & 21.8 & 21.3 & 4.6 & 53.3 & & \\
\hline L. unicornis & 10 & 5.5 & 6.0 & 1.4 & 60.0 & & \\
\hline Total & 50 & - & 27.3 & 5.6 & 54.6 & & \\
\hline
\end{tabular}

Table 3. Results of selectivity experiment conducted at equal prey density under conditions of increased shelter. Statistical notation and analysis are the same as in Table 1

\begin{tabular}{|lcccccc|}
\hline Species & Initial & \multicolumn{3}{c}{ Mean number consumed } & Percent & \multicolumn{2}{c|}{$\begin{array}{c}\text { Chi-square } \\
\text { density }\end{array}$} & expected & observed & SD & consumed & pooled & heterogeneity \\
\hline E. levis & 25 & 8.8 & 4.7 & 2.8 & 18.8 & $7.94 \cdots$ \\
L. unicornis & 25 & 8.8 & 12.8 & 5.0 & 51.2 & 7.80 \\
Total & 50 & - & 17.5 & 6.7 & 35.0 & \\
$\ldots \mathrm{p}<.01$ & & & & & & \\
\hline
\end{tabular}

during the same period (Clements and Livingston, 1983).

\section{RESULTS}

When equal numbers of 2 prey species were present, Lembos unicomis was disproportionately consumed by filefish, regardless of whether the alternative species was Elasmopus levis or Melita appendiculata (Table 1). The pooled chi-square was significant in both experiments, indicating that observed frequencies of the 2 species consumed deviated from expected values. When initial prey ratios were shifted from $1: 1$ to $4: 1$, in favor of either $E$. levis or $M$. appendiculata, the observed and expected numbers consumed were not significantly different, indicating that feeding behavior was random when abundance of these 'less preferred' species was increased (Table 2).
Increasing the amount of algae in the aquaria inhibited the ability of filefish to locate and/or capture Lembos unicornis and Elasmopus levis. The mean number of amphipods consumed (both species) in the $90 \mathrm{~g}$ algae treatment (Table 3) was significantly less than that in the $45 \mathrm{~g}$ treatment $(17.5$ and 32.8 , respectively; $\mathrm{t}=3.94$, $\mathrm{df}=10, \mathrm{p}<.01$ ). Although predation intensity was reduced under conditions of increased shelter, L. unicornis was still disproportionately consumed by filefish.

Experiments measuring attack rates on Lembos unicornis and Elasmopus levis separately indicated that the former species was more vulnerable to predation by filefish (Table 4). Both the total number of attacks and the number of successful attacks per 5 min search time were significantly greater on $L$. unicornis. The proportion of successful attacks on L. unicornis was, however, not significantly greater than on $E$.

Table 4. Attack rates on Elasmopus levis and Lembos unicornis per 5 min search time in separate aquaria. $\mathrm{N}=6$ for each species

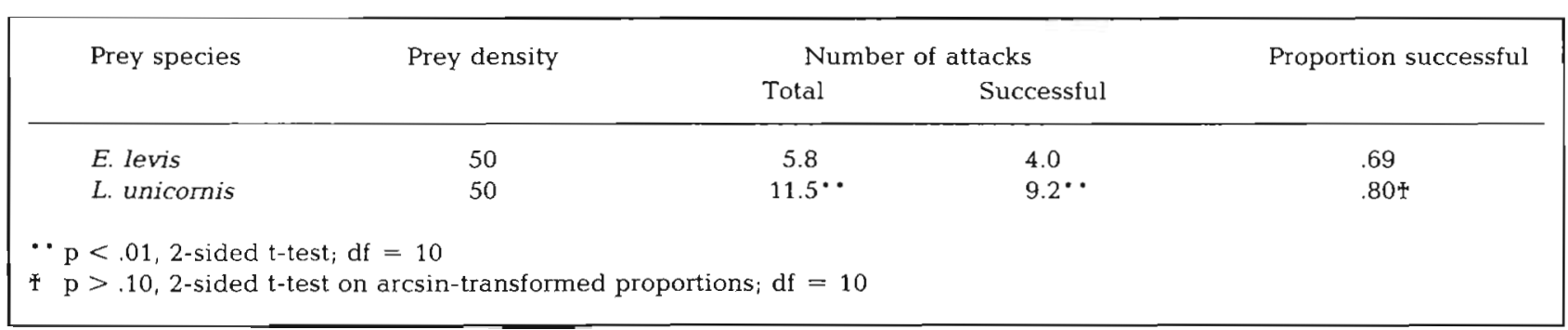


levis, suggesting that the two species were about equal in their ability to escape predation once attacked.

Prey selectivity of Monacanthus ciliatus in the field was similar to results of our experiments. Jacobs' (1974) measure of food selection was calculated for Lembos unifasciatus $(0.41)$ and Elasmopus levis $(-0.21)$. This index is analogous to Ivlev's (1961) index of electivity, with positive values indicating a particular food item was selected for and negative values indicating it was avoided. However, unlike Ivlev's (1961) model, this index is not dependent on relative prey abundance in the environment, thus making it possible to compare food items with different relative abundances (Jacobs, 1974). Conclusions derived from these field data are obviously subject to the same criticisms mentioned in the 'Introduction'. However, the similarity of these data to results of our laboratory experiments suggests that the relative vulnerability of these species to predation in the field was not simply a sampling artifact.

\section{DISCUSSION}

The vulnerability of a species to predation is a function of its detectability and ease of capture (Paloheimo, 1979), which, in turn are dependent on its morphology, behavior, and microhabitat distribution (Ware, 1973; O'Brien et al., 1976; Stein and Magnuson, 1976; Stein, 1977). In our experiments, amphipods were randomly distributed on the algal substrate and thus microhabitat preferences of these animals could not explain the observed patterns of prey selectivity. There were also no apparent behavioral differences between prey, as each species was relatively inactive and remained on the algal substrate unless attacked by a filefish. Morphological differences however, could account for the disproportionate consumption of Lembos unicornis in these experiments. Elasmopus levis and Melita appendiculata are both relatively unpigmented species. In contrast, each of the body segments and coxal plates of L. unicornis, except thoracic segments 1 and 7 , are darkly pigmented. The lack of pigment from these segments gives this species a very characteristic banding pattern (Myers, 1981). Zaret (1972) proposed a 'visibility hypothesis' to explain the apparent selectivity of vertebrate planktivores for prey with large amounts of pigmentation. Vulnerability of the cladoceran Bosmina longirostris to predation was proportional to the amount of pigment concentrated in its compound eye (Zaret and Kerfoot, 1975). Results of our experiments suggest an analogous explanation for the greater risk of $L$. unicornis to predation by filefish. This species was attacked more frequently owing to its greater rate of encounter. We hypothesize that vul- nerability of $L$. unicornis to predation was a function of its unique pattern of pigmentation.

Lembos unifasciatus was disproportionately consumed by filefish in Apalachee Bay. Stoner (1979) noted that pinfish Lagodon rhomboides collected from the same area were also strongly selective for this species. Lembos unifasciatus does possess a distinct band of pigment on its fifth thoracic segment (Myers, 1981), which may have increased its detectability. Thus, based on results of our laboratory experiments with $L$. unicornis, we suggest that vulnerability of L. unifasciatus to predation by filefish and pinfish in Apalachee Bay was possibly a consequence of its greater encounter rate.

We recommend that patterns of prey selectivity observed in the field should be qualified by laboratory experiments to determine the relative importance of active prey selection (i.e. resulting from differences in predator preferences) and passive selection (resulting from differences in prey accessibility). This approach is especially critical when field results are interpreted in terms of optimal foraging theory, which assumes an optimal diet is obtained via predator preferences. Although optimal foraging theory is generally well supported by experimental evidence, estimates of prey accessibility and encounter rates should be included in these models (Werner and Hall, 1974; Vinyard and O'Brien, 1976; Mittlebach, 1981; Werner et al., 1981). Zaret and Kerfoot (1975) note that the assumption planktivores select prey only on the basis of energetics is simplistic. For example, observed preference of vertebrate planktivores for larger prey (Brooks and Dodson, 1965), while in accordance with optimal foraging theory, may simply be a consequence of the greater detectability of larger zooplankton (O'Brien et al., 1976). Thus it is quite possible for a predator to obtain passively an optimal diet by 'selecting' prey that are encountered more frequently and therefore reducing the amount of time devoted to searching. However, active and passive prey selection involve very different assumptions in terms of optimal foraging theory and therefore should be treated as distinct phenomena.

Acknowledgements. We are especially grateful to the staff of the Florida State University Marine Laboratory for logistical support. K. Leber and K. Main assisted in collecting experimental animals. K. Leber, G. Lewis, B. Mahoney, A. Stoner, and J. Travis made helpful comments on earlier drafts of the manuscript. Special thanks to A. Thistle for editing and typing the final draft.

\section{LITERATURE CITED}

Brooks, J. L., Dodson, S. I. (1965). Predation, body size, and composition of plankton. Science, N. Y 150: 28-35

Chesson, P. (1978). Measuring preference in selective predation. Ecology 59: 211-215 
Clements, W. H., Livingston, R. J. (1983). Overlap and pollution-induced variability in the feeding habits of filefish (Pisces:Monacanthidae) in Apalachee Bay, Florida. Copeia 1983: 331-338

Greenwood, J. J. D., Elton, R. A. (1979). Analysing experiments on frequency-dependent selection by predators. J. Anim. Ecol, 48: 721-737

Ivlev, V. S. (1961). Experimental ecology of the feeding of fishes. Yale University Press, New Haven

Jacobs, J. (1974). Quantitative measurement of food selection: a modification of the forage ratio and Ivlev's selectivity index. Oecologia (Berl.) 14: 413-417

Johnson, D. H. (1980). The comparison of usage and availability measurements for evaluating resource preference. Ecology 61: 65-71

Lewis, F. G., III (1982). Habitat complexity in a subtropical seagrass meadow: the effects of macrophytes on species composition and abundance in benthic crustacean assemblages. Ph. D. Dissertation, Florida State University, Tallahassee, Florida

Livingston, R. J. (1975). Impact of kraft pulp-mill effluents on estuarine and coastal fishes in Apalachee Bay, Florida, USA. Mar. Biol. 32: 19-48

Mittlebach, G. G. (1981). Foraging efficiency and body size: a study of optimal diet and habitat use by bluegills. Ecology 62: $1370-1386$

Myers, A. A. (1981). Amphipod crustacea. I. Family Aoridae. Memoirs of the Hourglass cruises, Vol. 5. Florida Department of Natural Resources Marine Research Laboratory St. Petersburg, Florida

O'Brien, W. J., Vinyard, G. L. (1974). Comment on the use of Ivlev's electivity index with planktivorous fish. J. Fish. Res. Bd Can. 31: 1427-1429

O'Brien, W. J., Slade, N. A., Vinyard, G. L. (1976). Apparent size selection as the determinant of prey selection by bluegill sunfish (Lepomis macrochirus). Ecology 57: $1304-1310$
Paloheimo, J. E. (1979). Indices of food type preference by a predator. J. Fish. Res. Bd Can. 36: 470-473

Stein, R. A. (1977). Selective predation, optimal foraging and predator-prey interaction between fish and crayfish. Ecology 58: $1237-1253$

Stein, R. A., Magnuson, J. (1976). Behavioral response of crayfish to a fish predator. Ecology $57: 571-581$

Stoner, A. W. (1979). Species specific predation on amphipod crustacea by the pinfish Lagodon rhomboides: mediation by macrophyte standing crop. Mar. Biol. 55: 201-207

Stoner, A. W. (1980). The role of seagrass biomass in the organization of benthic macrofaunal assemblages. Bull. mar. Sci. 30: 537-551

Strauss, R. E. (1979). Reliability estimates for Ivlev's electivity index, the forage ratio, and a proposed linear index of food selection. Trans. Am. Fish. Soc. 108: 344-352

Vinyard, G. L., O'Brien, W. J. (1976). Effects of light and turbidity on the reactive distance of bluegill (Lepomis macrochirus). J. Fish. Res. Bd Can. 33: 2845-2849

Ware, D. M. (1973). Risk of epibenthic prey to predation by rainbow trout (Salmo gairdneri). J. Fish. Res. Bd Can. 30 787-797

Werner, E. E., Hall, D. J. (1974). Optimal foraging and the size selection of prey by bluegill sunfish (Lepomis macrochirus). Ecology 55: 1042-1052

Werner, E. E., Mittelbach, G. L., Hall, D. J. (1981). The role of foraging profitability and experience in habitat use by the bluegill sunfish. Ecology 62: 116-125

Zar, J. H. (1974). Biostatistical analysis. Prentice-Hall, Inc., Englewood Cliffs

Zaret, T. M. (1972). Predators, invisible prey, and the nature of polymorphism in the Cladocera (Class: Crustacea). Limnol. Oceanogr 17: 171-184

Zaret, T. M., Kerfoot, W. C. (1975). Fish predation on Bosmina longirostris: body size selection versus visibility selection. Ecology 56: 232-237 